\title{
Acquired idiopathic sideroblastic anemia
}

INSERM

\section{Source}

INSERM. (1999). Orphanet: an online rare disease and orphan drug data base. Acquired idiopathic sideroblastic anemia. ORPHA:75564

Acquired idiopathic sideroblastic anaemia is one of a group of disorders known as the myelodysplastic syndromes (MDS) characterised by ineffective haemopoiesis affecting one or more blood cell lineages (myeloid, erythroid or megakaryocytic) leading to peripheral blood cytopenias and an increased risk of developing leukaemia. Acquired idiopathic sideroblastic anaemia is now more commonly referred to as refractory anaemia with ring ed sideroblasts or the acronym RARS. 